\title{
Short-term dewatering of treated oil sand fine tailings
}

\author{
John Owolagba and Shahid Azam*
}

\begin{abstract}
Background: The appropriate management of oil sand tailings requires a reduced environmental footprint of the waste containment facilities. This study models the short-term dewatering behavior of a $10 \mathrm{~m}$ deep deposit.

Results: Results indicated that inherent material properties along with hydraulic boundary conditions govern the rate and amount of consolidation.

Conclusions: The process alone is not sufficient for meaningful tailings dewatering in one year and must be augmented by other methods to further improve the tailings disposal scheme.
\end{abstract}

Keywords: Environmental footprint, Oil sand tailings, Consolidation model

\section{Background}

Extraction processes in the oil sand industry (northern Alberta, Canada) produces significant amount of waste slurries $\left[0.25 \mathrm{~m}^{3} /\right.$ barrel of crude oil produced (Mikula et al. 1996)] characterized by caustic pore fluids and ore minerals suspended in bitumen contaminated liquids. The ever increasing volume and slow densification rates of such loose and toxic tailings require large storage areas prompting the need for dewatering improvements prior to and upon deposition in disposal facilities. The waste stream is known as mature fine tailings (MFT) because it achieves about $30 \%$ solids (by weight) within a couple of years. Anymore water release is usually not possible without physical and/or chemical amelioration and, as such, the MFT volume continues to increase over time (Azam et al. 2007). Furthermore, the containment structures are notorious for a high failure rate and can result in economic, social, health, and environmental issues (Azam and Li 2010).

To reduce tailings footprint, several pre-deposition technologies have been developed with various degrees of success (Devenny 2010). For example, in-line-thickening through polymeric flocculation of

\footnotetext{
*Correspondence: Shahid.Azam@uregina.ca

Environmental Systems Engineering, Faculty of Engineering and Applied Science, University of Regina, 3737 Wascana Parkway, Regina, SK S4S 0A2, Canada
}

particles (Jeeravipoolvarn 2010) and centrifugation at accelerations higher than gravity (Mikula et al. 2008) have resulted in MFT solids in the range of $50-60 \%$. A clear understanding of post-deposition consolidation of the relatively denser waste streams in dedicated disposal facilities is required as part of the tailings management scheme. The purpose of this note is to predict the dewatering behaviour of treated oil sand tailings over a short-term.

\section{Model development}

A one-dimensional finite-strain formulation [developed by Jeeravipoolvarn (2010)] was used. The model was based on the following form of the slurry consolidation equation (Somogyi 1980) that used depth coordinate $(z)$ along with material properties [unit weight of water $\left(\gamma_{w}\right)$, specific gravity of solids $\left(G_{s}\right)$ void ratio $(e)$, and hydraulic conductivity $(k)]$ as well as excess pore pressure $(u)$ and time $(t)$ :

$$
\frac{\partial}{\partial z}\left[-\frac{k}{\gamma_{w}(1+e)} \frac{\partial u}{\partial z}\right]+\frac{d e}{d \sigma^{\prime}}\left[\left(G_{s}-1\right) \gamma_{w} \frac{d(\Delta z)}{d t}-\frac{\partial u}{\partial t}\right]=0
$$

An implicit finite difference method, that yielded a set of linear equations, was employed to solve the above governing equation. A $10 \mathrm{~m}$ deep deposit was simulated for 1 year duration using material properties [reported by Owolagba and Azam (2015a)] along with appropriate 
field conditions. The model output was selected to be in the form of effective stress $\left(\sigma^{\prime}\right)$ profile.

Material properties of treated MFT included specific gravity $\left(G_{s}=2.4\right)$, solids content $(s=60 \%)$, void ratio $(e=1.5)$ and non-linear constitutive relationships. The above initial conditions ( $s$ and $e$ ) meant negligible sedimentation thereby precluding the capture of this phase of dewatering (Azam et al. 2009). This provided the rationale to use Eq. (1) for simulating slurry consolidation along with the coefficients of the volume compressibility relationship $\left(e=13.6 \sigma^{\prime-0.3}\right)$ and the hydraulic conductivity relationship $\left(k=1.3 \times 10^{-10} e^{2.3}\right)$ : where $\sigma^{\prime}$ is effective stress and $k$ is hydraulic conductivity.

The hydraulic boundary included atmospheric conditions on top of the deposit and, as such, the surface could be affected by precipitation and evaporation. However, the climatic conditions in northern Alberta ensure that surface evaporation is negligible during eight months of the year and intermittent rainfall can offset the influence of desiccation during the summer months (Owolagba and Azam 2015b). Furthermore, the low hydraulic conductivity of the slurry means minimal storm water ingress into the deposit thereby resulting in surface runoff. Likewise, seepage at the bottom of the deposit was considered to be negligible because of the dominance of clays in the supporting soils (Morgenstern and Scott 1997). Therefore, most of the water flow through the slurry is in the upward direction.

\section{Model results}

Consolidation refers to the expulsion of excess pore water pressure over time to achieve a gradually compressed soil, as indicated by a corresponding increase in effective stress. Figure 1 depicts the effective stress profile for the $10 \mathrm{~m}$ deep treated MFT deposit. The plot shows a three stage pattern as follows: (1) significant increase in effective stress from 0 to $1460 \mathrm{~Pa}$ at surface (up to $0.5 \mathrm{~m}$ depth); (2) negligible increase in effective stress in the intermediate zone (0.5-9.5 m); and (3) marginal increase in effective stress from 1465 to $1650 \mathrm{~Pa}$ at bottom (9.5$10 \mathrm{~m}$ ). After one year, the poor consolidation behavior of the investigated tailings (indicated by the low effective stress of $<2 \mathrm{kPa}$ ) is attributed to the low hydraulic conductivity and relatively high initial solids content of the material (Ito and Azam 2013).

The above data shows that electrochemical interactions between the slurry constituents govern the initial dewatering behavior of treated MFT. According to Azam and Rima (2014), the oil sand fine tailings are characterized by clays (clay size fraction $=50 \%$ and clay mineral species $=40 \%)$ that are suspended in an ion-rich liquid $(\mathrm{pH}=8.2$, electrical conductivity $=3300 \mu \mathrm{S} / \mathrm{cm}$ and total dissolved solids $=2400 \mathrm{mg} / \mathrm{L}$ ). The resulting card house fabric is found to hold water due to hydration of

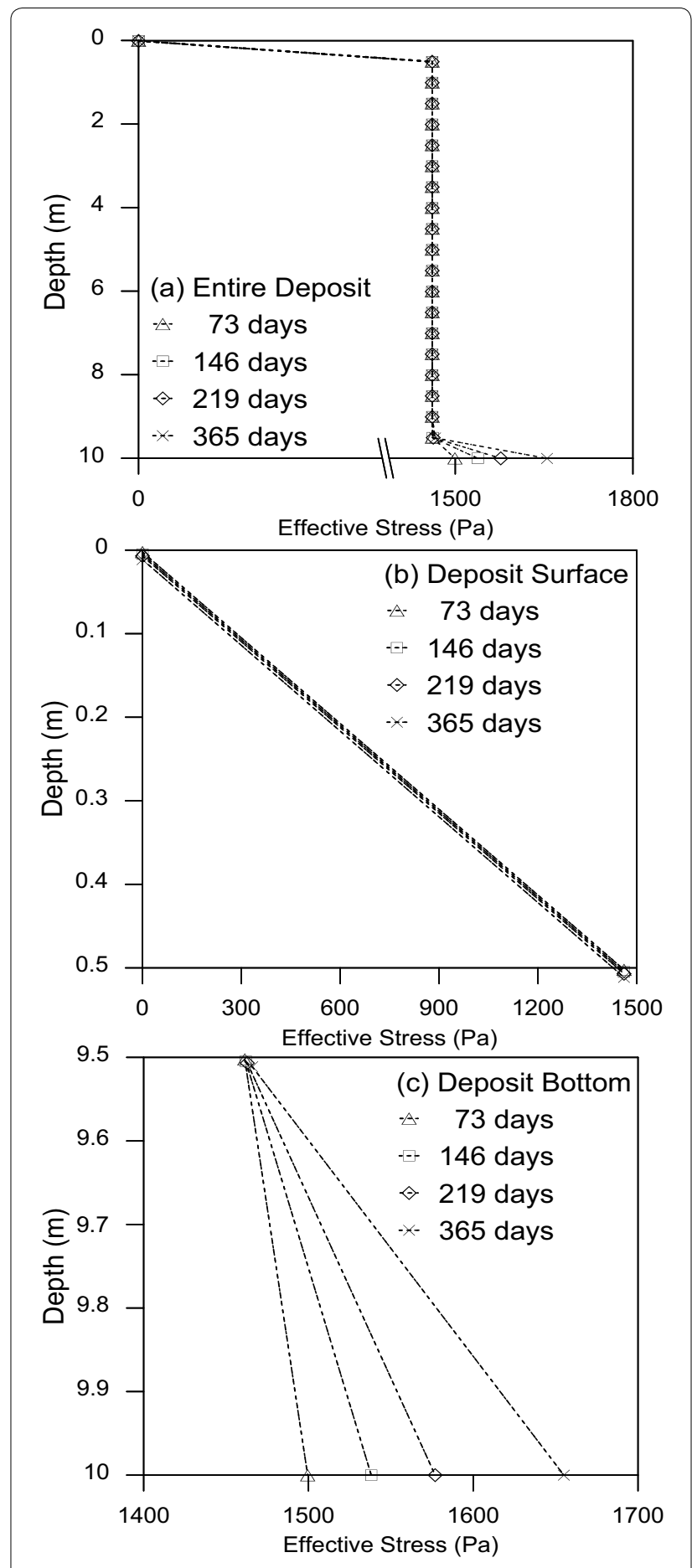

Fig. 1 Effective stress profile for $10 \mathrm{~m}$ deep oil sand tailings deposit

clay minerals, presence of immiscible residual bitumen, micron-size pore network, and convoluted flow paths with dead ends (Jeeravipoolvarn 2010).

Upon deposition, the MFT release water (resulting in an initial effective stress increase) by drainage through 
the free surface as the slurry develops the above-mentioned microstructure. Figure 1b (deposit surface) shows that surface drainage occurs at the same rate and irrespective of the duration in the top $0.5 \mathrm{~m}$ of the deposit thereby confirming the fabric effects. Thereafter, only minor amount of water release (along with low effective stress increase) occurs because most of the void spaces are effectively blocked by residual bitumen present in the slurry. Overtime, some particle re-adjustment and flow channeling under the overlying slurry weight can take place to cause marginal water release and with an associated increase in effective stress. Figure 1c (deposit bottom) shows the gradual development of flow channels with time at the bottom $0.5 \mathrm{~m}$ of the deposit.

The above results for treated MFT $(s=60 \%)$ correlate well with published data on untreated MFT $(s=30 \%)$. Ito and Azam (2013) predicted an effective stress of 500-900 Pa after 300 days at the bottom of a $1.0 \mathrm{~m}$ high column. Likewise, Azam and Rima (2014) measured an increase of only $7 \%$ in solids content in a laboratory centrifuge at $2550 \mathrm{~g}$ and Jeeravipoolvarn et al. (2009) measured an effective stress of $5 \mathrm{kPa}$ after 24.6 years in a $10 \mathrm{~m}$ standpipe. This confirms the high water holding capacity of MFT that does not change with treatment.

\section{Conclusion}

This work indicated that inherent material properties along with hydraulic boundary conditions govern the rate and amount of dewatering of treated MFT. The process of consolidation alone is not sufficient for appreciable tailings consolidation. Short-term dewatering mainly occurs through surface drainage and particle re-adjustment and flow channeling appear over time. Further modification is required to augment consolidation such as through accelerated dewatering (vick drains) and atmospheric drying (thin lifts).

\section{Authors' contributions}

JO carried out numerical modeling and drafted the manuscript. SA provided conceptual guidance and polished and revised the manuscript. Both authors read and approved the final manuscript.

\section{Acknowledgements}

The authors acknowledge the financial support provided by the Natural Science and Engineering Research Council of Canada and the computation facilities provided by the University of Regina.

\section{Competing interests}

The authors declare that they have no competing interests.

Received: 13 July 2016 Accepted: 1 January 2017

Published online: 10 January 2017

\section{References}

Azam S, Li Q (2010) Tailings dam failures: a review of the last one hundred years. Geotech News 28(4):50-53

Azam S, Rima US (2014) Oil sand tailings characterization for centrifuge dewatering. Environ Geotech 1(3):189-196

Azam S, Scott JD, Jeeravipoolvarn S (2007) When does a slurry become a soil? Geotech News 25(3):44-46

Azam S, Jeeravipoolvarn S, Scott JD (2009) Numerical modeling of tailings thickening for improved mine waste management. J Environ Inform 13(2):111-118

Devenny DW (2010) A screening study of oil sand tailings technologies and practices. Alberta Energy Research Institute, Edmonton

Ito M, Azam S (2013) Large-strain consolidation modeling of mine waste tailings. Environ Syst Res 2(7):1-12

Jeeravipoolvarn S (2010) Geotechnical behavior of in-line thickened oil sands tailings. Ph.D. thesis, Department of Civil \& Environmental Engineering, University of Alberta, Edmonton, Canada

Jeeravipoolvarn S, Scott JD, Chalaturnyk RJ (2009) 10 m standpipe tests on oil sands tailings: long-term experimental results and prediction. Can Geotech J 46:875-888

Mikula RJ, Kasperski KL, Burns RD, Mackinnon MD (1996) Nature and fate of oil sands fine tailings. Adv Chem Ser 251:677-723

Mikula RJ, Munoz VA, Omotoso O (2008) Centrifuge options for production of "dry stackable tailings" in surface mined oil sands tailings management. In: Canadian international petroleum conference, Calgary, Canada

Morgenstern NR, Scott JD (1997) Oil sand geotechnique. Geotechn News 15(4):I02-109

Owolagba J, Azam S (2015a) Geotechnical properties of centrifuged oil sand fine tailings. Environ Geotech 2(5):309-316

Owolagba J, Azam S (2015b) Effect of seasonal weather variations on the desiccation behavior of treated oil sand fine tailings. Environ Earth $\mathrm{Sci}$ 74(2):1711-1717

Somogyi F (1980) Large strain consolidation of fine grained slurries. Canadian Society for Civil Engineering, Winnipeg

\section{Submit your manuscript to a SpringerOpen ${ }^{\circ}$ journal and benefit from:}

- Convenient online submission

- Rigorous peer review

- Immediate publication on acceptance

- Open access: articles freely available online

- High visibility within the field

- Retaining the copyright to your article

Submit your next manuscript at springeropen.com 